\title{
Invariance of Double Layer Capacitance to Polarized Potential in Halide Solutions
}

\author{
Yongdan Hou, Koichi Jeremiah Aoki ${ }^{*}$, Jingyuan Chen, Toyohiko Nishiumi \\ Department of Applied Physics, University of Fukui, 3-9-1, Fukui, 910-0017, Japan \\ *Corresponding Author: kaoki@u-fukui.ac.jp
}

Copyright () 2013 Horizon Research Publishing All rights reserved.

\begin{abstract}
This paper aims at evaluating the dependence of double-layer capacitance at a platinum wire electrode both on concentrations of four kinds of halide ions and the dc potential in the double-layer region (from 0.0 to $0.4 \mathrm{~V}$ vs. $\mathrm{Ag} \mid \mathrm{AgCl}$ ) from a viewpoint of frequency-dispersion of the capacitance. Attention was paid to shape of the double layer capacitance vs. dc-potential curves. The equivalent circuit used for analysing the double-layer impedance was a parallel combination of a double layer capacitance and an apparent resistance. The latter is caused by the time-derivative of the capacitance, which belongs to an in-phase component. It was inversely proportional to the frequency and the electrode area, but unaffected by the potential and the variation of concentrations of halide ions. On the other hand, the parallel capacitance decreased linearly with logarithm of the frequency, and was proportional to the electrode area. It showed almost a value common to concentrations from 1 $\mathrm{mM}$ to $2 \mathrm{M}\left(=\mathrm{mol} \cdot \mathrm{dm}^{-3}\right)$ and four halide ions. Variations of the capacitance with the dc-potential in $0.1 \mathrm{M} \mathrm{KF}, \mathrm{KCl}$ and $\mathrm{KBr}$ solutions are ca. $10 \%$. Therefore, the capacitance has negligible influence on the localization of ions by the Gouy-Chapman theory.
\end{abstract}

Keywords Impedance Measurement, Capacitance and Resistance of Electrical Double Layer, Gouy-Chapman Theory, Halide

\section{Introduction}

An important property of electric double layers is the dependence of the double layer capacitance, $C_{\mathrm{d}}$, on dc-potential, $E$, at an electrode. The dependence can provide excess charge on the electrode by integration of $C_{\mathrm{d}}$ with respect to $E$. The potential dependence has been classified roughly into three types $[1,2]$; a U-shape as predicted from the Gouy-Chapman (GC) theory [3, 4], a bell-shape as predicted from the Modified Poisson-Boltzmann equation [5-7], and a camel-shape as predicted from the Gouy-Chapman-Stern model. In addition, some authors reported variations small enough for the classification [8-15].
It is interesting to search conditions exhibiting these shapes.

We surveyed here thirty four documents, and classified shapes of $C_{\mathrm{d}}$ vs. $E$ curves into a valley[3, 8, 12, 13, 16-21], one peak $[1,2,22-27]$, two peaks $[1,2,17,26,28-32]$, a plane [8-15, 33-36] and exceptions[9, 17, 25, 34, 37, 38].The classification is based on whether a curve varies by over $30 \%$ of the relative variation, $\Delta C / C_{\mathrm{av}}$, where $C_{\mathrm{av}}$ is the arithmetic mean of the variations of $C_{\mathrm{d}}$ with $E$. The number of the classified publications is shown in Fig. 1A for every available electrode. The classified distributions depend on electrode materials; the valley being predominant at mercury $[8,16-19,21]$, the one peak being predominant at platinum $[23,25,39]$, a plane being at carbon $[9,10,12,14$, 34]. The plane seems to be observed when non-ionic substances are adsorbed on electrodes [16, 17], especially for carbon. The percentage of the classified shapes without distinction of electrodes is shown on the right ordinate in Fig. 1B. Although the valley-shape has been widely acknowledged as a proof of the GC theory, it accounts for only a quarter of the number of the reports. The percentage for reports by computer simulation $[1,2,27,35]$ is also in Fig. 1B. The simulated results, including only few reports on the plane-shape, are not in accord with the experimental results, probably because most researchers on the simulation have paid attention to ionic interactions which depend strongly on potential.

Although the shape is a noticeable feature, the classification depends on values of $\Delta C / C_{\mathrm{av}}$. We classified experimental $C_{\mathrm{d}}$, with $E$ curves by values of $\Delta C / C_{\mathrm{av}}$, which is shown in Fig. 2. Seventy percent of the curves belong to the group with $\Delta C / C_{\mathrm{av}}<0.9$ in Fig. 2A. Figure $2 \mathrm{~B}$ shows assignment of $\Delta C / C_{\mathrm{av}}$ to electrode materials. Curves with $\Delta C / C_{\mathrm{av}}>0.61$ are nearly assigned to $\mathrm{Hg}[8,16-19,21]$ and $\mathrm{Ag}$ $[22,28,30]$. Platinum $[8,25,38]$, gold $[13,20,29,31]$ and carbon $[8-10,12,14,34]$ show small variations of $\Delta C / C_{\mathrm{av}}$. In contrast, the theoretical prediction is opposite to the above. The mean field approximation has presented 11 curves[1, 2]for $\Delta C / C_{\mathrm{av}}>0.91$, and 2 curves[2, 27]for $0.61<\Delta C / C_{\mathrm{av}}<$ 0.90. The ion-cell model[35] on the assumption of non-overlap of ions has predicted a plane-shape curve with $\Delta C / C_{\mathrm{av}}<0.3$ at high salt concentrations. 


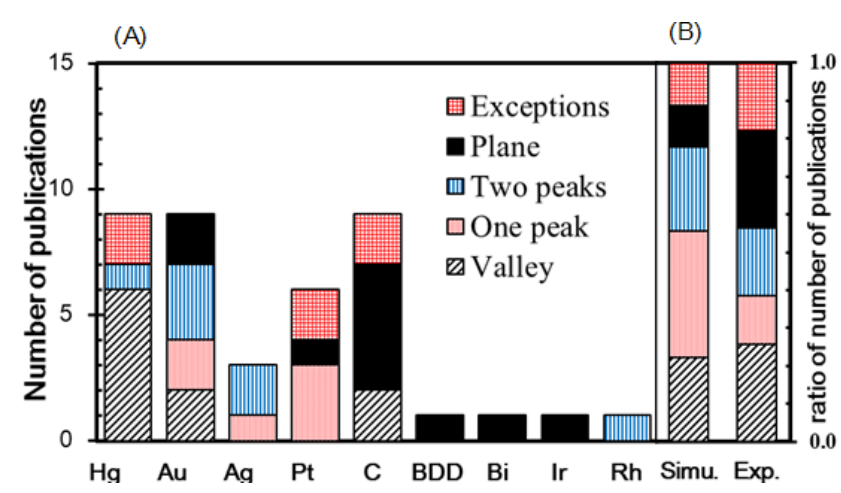

Figure 1. Change classification of 34 publications aboutthe double layer capacitancesvs. potential curves into five shapes; (A) the number of publications for every available electrode material and (B) ratio of number of publications belonging to a given shape for simulation and experimental work.

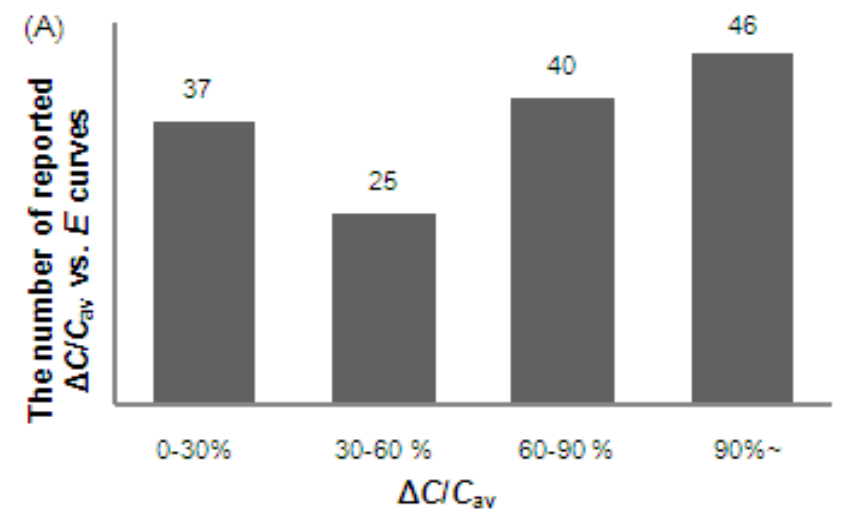

(B)
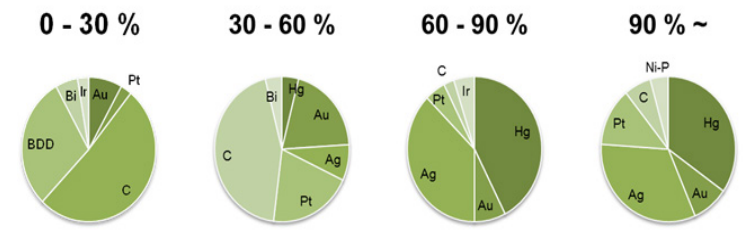

Figure 2. The number of experimental capacitance vs. potential curves classified with values of $\Delta C / C_{\text {av }}$ (A) without and (B) with assignment to electrode materials.

The GC theory mentions that application of positive voltage to an electrode [33] enhances concentration of anions near the electrode by the electrostatic force to increase the capacitance. The dependence of $C_{\mathrm{d}}$ on $E$ should be related with that on ionic concentrations. The capacitance has been demonstrated to be independent of concentrations of chloride ions[40], and hence may be controlled by solvents rather than ions. It is necessary to examine the $C_{\mathrm{d}}$ vs. $E$ curves in the context of the dependence on the ionic concentration.

An electrode frequently used for measurements of double layer capacitances is a disk, the circumference of which is coated with an insulator. A boundary between the exposed electrode and the insulating wall yields floating capacitance, depending on fabrication of electrodes, periods of use of electrodes, and dc-potential. A technique of suppressing the floating capacitance is to use a wire electrode without insulator. The area of the exposed surface is determined by the immersion length of the electrode [40]. A wire electrode may be helpful for accurate and reproducible determination of $C_{\mathrm{d}}$ vs. $E$ curves.

This report deals with obtaining the relations of the capacitance to the dc-potential and the concentrations of four halide ions at the platinum wire electrode by ac-impedance. It has been believed that $\mathrm{F}^{-}$is non-specifically adsorbed on mercury electrodes whereas $\mathrm{Cl}^{-}, \mathrm{Br}^{-}$, and $\mathrm{I}^{-}$are specifically adsorbed $[17,18,41]$. This is not consistent with the finding that the capacitance is caused by solvent molecules rather than ions at platinum electrodes [40]. Our concern here is to examine whether thiswell-known knowledge at mercury is valid at platinum electrodes in the polarized potential domain, taking into account the frequency dispersion of the capacitance.The double layer capacitance used here is the net capacitance without parallel resistance of the double layer.

\section{Materials and Methods}

\subsection{Chemicals}

$\mathrm{KF}, \mathrm{KCl}, \mathrm{KBr}$ and $\mathrm{KI}$ solutions were prepared by analytical grade chemicals and ion-exchanged distilled water $(18 \mathrm{M} \Omega \mathrm{cm})$. HF solutions were stored in polyethylene (PE) containers.

\subsection{Impedance Measurement at Platinum Wire Electrodes}

Working electrodes were platinum wires $0.1 \mathrm{~mm}$ in diameter, $10 \mathrm{~mm}$ in length immersed into solution. An $\mathrm{Ag} \mid \mathrm{AgCl}$ (in saturated $\mathrm{KCl}$ ) and a platinum coil $(0.5 \mathrm{~mm}$ in diameter, $120 \mathrm{~mm}$ in length) were used for a reference electrode and a counter electrode, respectively. The platinum wire and coil were cleaned according to our early work [40]. A salt bridge including the sample solution was set between the reference electrode and the bulk solution via a glass filter. All electrolytes were deaerated by nitrogen gas for $20 \mathrm{~min}$ before electrochemical experiments.

The potentiostat was Compactstat (Ivium, Netherlands), equipped with a lock-in amplifier. Applied alternating voltage was $10 \mathrm{mV}$ in amplitude. The dc-potential domain on which the ac-voltage was superimposed was selected on the basis of $30 \%$ enhancement of the cyclic voltammetric current from the linear increment of the voltammogram. It ranged from 0.0 to $0.4 \mathrm{~V}$ vs. $\mathrm{Ag} \mid \mathrm{AgCl}$. In-between every impedance measurement, cyclic voltammetry was made in order to confirm agreement between the voltammograms before and after the ac-impedance measurements.

Delay of the potentiostat was checked in our previous work [40]. No abnormality was observed so far as $\left|Z_{2}\right| / Z_{1}>$ 0.04 , where $Z_{1}$ and $Z_{2}$ are the real and the imaginary components of the ac impedance, respectively. For frequencies larger than $\left|Z_{2}\right| Z_{1}<0.04,\left|Z_{2}\right|$ values were overestimated. Most experimental conditions of the double 
layer measurements were in the domain of $\left|Z_{2}\right| / Z_{1}>0.04$.

\section{Results and Discussion}

\subsection{Concept of Impedance of Double Layers}

When ac voltage, $V=V_{\mathrm{o}} \exp (i \omega t)$, at the frequency, $\omega$, and the amplitude, $V_{0}$, is applied to an electric double layer, the responding current should be the time-derivative of the double layer charge, $q$, i.e., $I=\mathrm{d} q / \mathrm{d} t$. If the double layer capacitance, $C, \quad$ has frequency-dependence, the time-derivative of $q=C V$ is given by

$$
I=\frac{\mathrm{d}(C(\omega) V(t))}{\mathrm{d} t}=C(\omega) \frac{\mathrm{d} V(t)}{\mathrm{d} t}+V(t) \frac{\partial C(\omega)}{\partial \omega} \frac{\mathrm{d} \omega}{\mathrm{d} t}
$$

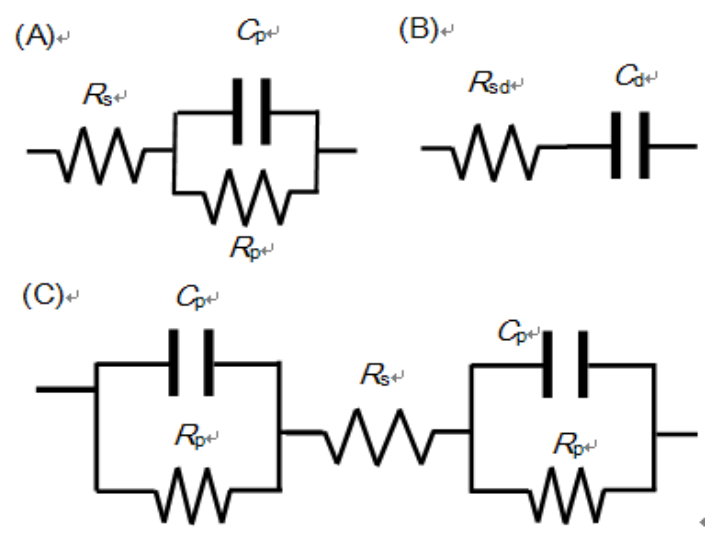

Figure 3. Equivalent circuits of the series combination of the double layer impedance and the solution resistance $R_{\mathrm{s}}$. The double layer impedance is composed of (A) a parallel combination of the capacitance, $C_{\mathrm{p}}$, and the resistance, $R_{\mathrm{p}}$.(B) is the conventional equivalent circuit, composed of a series combination of the solution resistance, $R_{\mathrm{sd}}$ and the double layer capacitance, $C_{\mathrm{d}}$. Circuit (C) corresponds to the impedance at identical two electrodes.

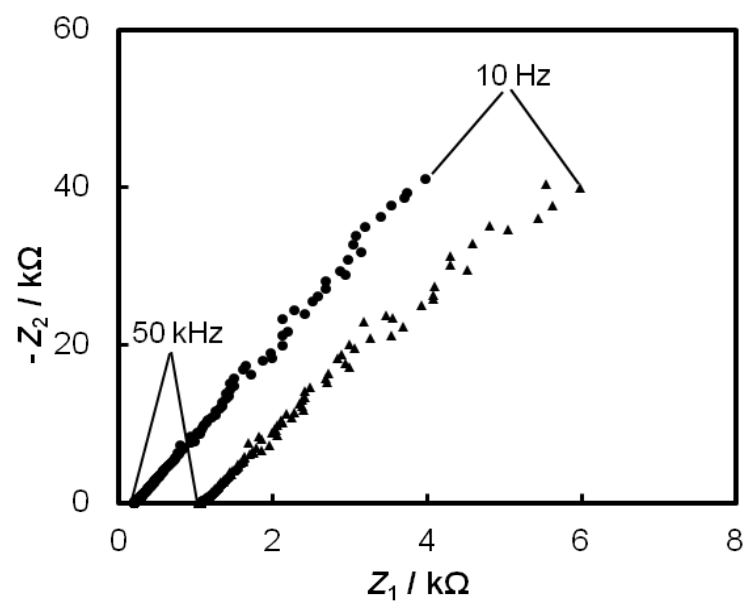

Figure 4. Nyquist plots for $0.01 \mathrm{M}\left(\mathrm{M}=\mathrm{mol} \mathrm{dm}{ }^{-3}\right) \mathrm{KF}$ and $\mathrm{KBr}$ solutions at the two wire electrodes with $7 \mathrm{~mm}$ separation.

The first term on the right hand side is $i \omega C V$, belonging to the out of phase. In contrast the second term includes no imaginary number, and hence belongs to the in phase, i.e. a resistive component. Since the current in (1) is a sum of the real and the imaginary current, the equivalent circuit can be represented as a parallel combination of $C$ (defined as $C_{\mathrm{p}}$ ) and the resistance $\left(1 /(\partial C / \partial t)=R_{\mathrm{p}}\right)$, as is illustrated in Fig. 3A including the solution resistance, $R_{\mathrm{s}}$. The conventional equivalent circuit is a series combination of the solution resistance, $R_{\text {sd }}$ and the double layer capacitance, $C_{\mathrm{d}}$, as shown in Fig. 3B.The equivalent circuit for the two identical electrodes is given in Fig. 3C.If the capacitance is invariant to $\omega$, as has been assumed conventionally, the current has only out of the phase component. When we applied this concept to the double layer impedance at the platinum electrode in $\mathrm{KCl}$ solution, we found a linear variation of $C_{\mathrm{p}}$ with $\log (\omega)$ [40]. Then the parallel resistance, $(\mathrm{d} t / \mathrm{d} \omega) /\left(\partial C_{\mathrm{p}} / \partial \omega\right)$, is proportional to $(\mathrm{d} t / \mathrm{d} \omega) / \omega$. We have already demonstrated the inverse proportionality of $R_{\mathrm{p}}$ to $\omega[40]$. So far as the double layer impedance is composed of an ideal capacitance, the parallel resistance cannot be taken into account in the analysis. Itcannot be incorporated into the analysis including the Nernst-Planck-Poisson equations[42], either.
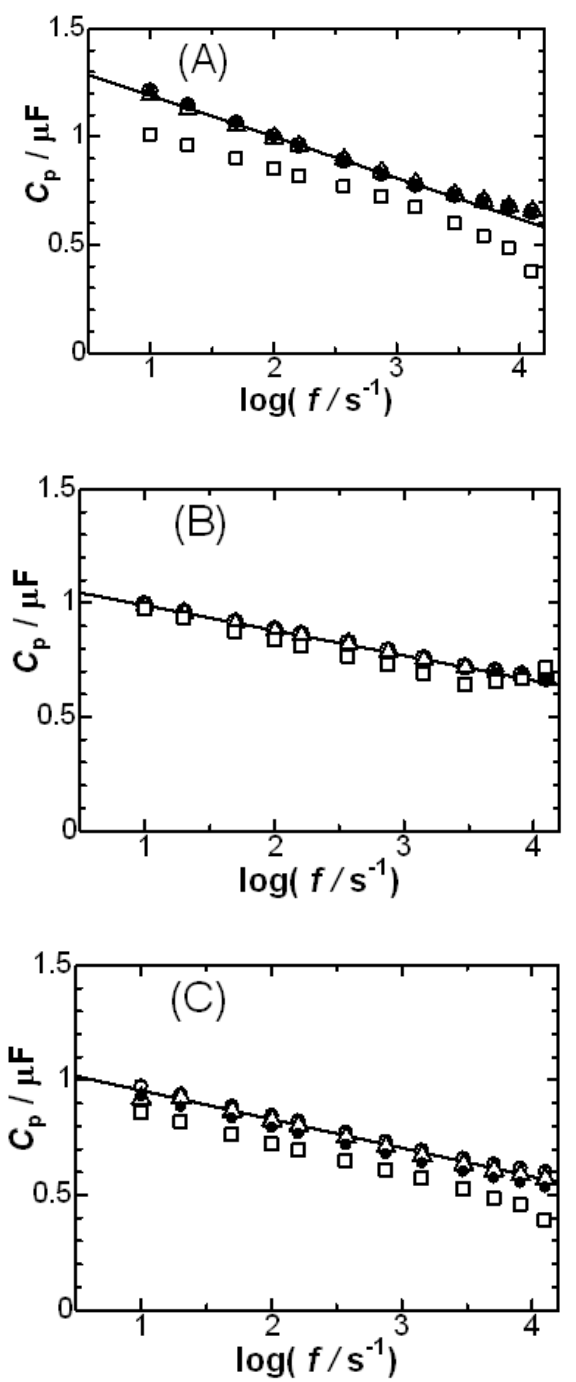


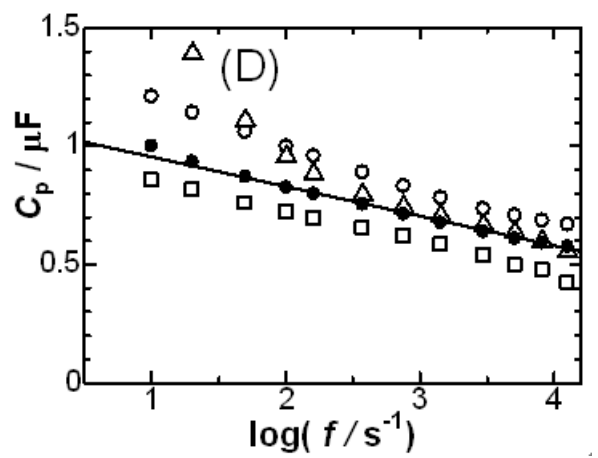

Figure 5. Variations of the parallel capacitances with logarithmic frequency for (A) $\mathrm{KF}$, (B) $\mathrm{KCl}$, (C) $\mathrm{KBr}$ and (D) $\mathrm{KI}$ at concentrations of (open circles) $2 \mathrm{M}$, (triangle) $0.5 \mathrm{M}$, (full circles) $0.1 \mathrm{M}$ and (squares) 0.01 M. Values of $C_{\mathrm{p}}$ were obtained at two electrodes without any reference electrode. $\mathrm{M}=\mathrm{mol} \cdot \mathrm{dm}^{-3}$ The conventional equivalent circuit, as is shown in Fig. 3(B), is a series combination of the double layer capacitance, $C_{\mathrm{d}}$, and the solution resistance, which includes the parallel resistance in the double layer, according to (1). Relations between the two equivalent circuits are given by

$$
\begin{gathered}
R_{\mathrm{sd}}=R_{\mathrm{s}}+\frac{R_{\mathrm{p}}}{1+\left(\omega C_{\mathrm{p}} R_{\mathrm{p}}\right)^{2}} \\
C_{\mathrm{d}}=C_{\mathrm{p}}+\frac{1}{\omega^{2} C_{\mathrm{p}} R_{\mathrm{p}}^{2}}
\end{gathered}
$$

The in-phase component, $R_{\mathrm{sd}}$, called "conventional solution resistance" is larger by the double layer resistance, $R_{\mathrm{p}} /\left[1+\left(\omega C_{\mathrm{p}} R_{\mathrm{p}}\right)^{2}\right]$ than the true solution resistance. Since $R_{\mathrm{p}}$ is inversely proportional to $\omega[40], R_{\mathrm{sd}}$ is approximated as $R_{\mathrm{s}}+$ $k / \omega$ for a constant $k$. On the other hand, the conventional double layer capacitance contains $1 / \omega^{2} C_{\mathrm{p}} R_{\mathrm{p}}{ }^{2}$. Since $\omega R_{\mathrm{p}}$ is independent of $\omega[40], C_{\mathrm{d}}$ may vary only slightly with $\omega$. If $R_{\mathrm{p}}$ is independent of dc-potential, $C_{\mathrm{d}}$ should have the dc-potential dependence similar to $C_{\mathrm{p}}$, according to (3).

The real impedance, $Z_{1}\left(=R_{\mathrm{sd}}\right)$, and the imaginary one, $Z_{2}$ $\left(=-1 / \omega C_{\mathrm{d}}\right)$, were obtained from the ac-current responding to the dc-superimposed ac-voltage at frequencies, $f(=\omega / 2 \pi)$, ranging from $1 \mathrm{~Hz}$ to $50 \mathrm{kHz}$. Extracting $C_{\mathrm{p}}$ and $R_{\mathrm{p}}$ from (2) and (3) yields

$$
\begin{gathered}
C_{\mathrm{p}}=\frac{-Z_{2}}{\omega} \frac{1}{\left(Z_{1}-R_{\mathrm{s}}\right)^{2}+Z_{2}^{2}} \\
R_{\mathrm{p}}=\frac{\left(Z_{1}-R_{\mathrm{s}}\right)^{2}+Z_{2}^{2}}{Z_{1}-R_{\mathrm{s}}}
\end{gathered}
$$

$R_{\mathrm{S}}$ was evaluated from the relation, $Z_{1}=R_{\mathrm{S}}+k / \omega$ for $f \rightarrow \infty$ or $Z_{2} \rightarrow 0$ in the Nyquist plot, as shown in Fig. 4. The plots are lines rather than hemi-circles, because the impedance contains no Faradaic process.Values of $C_{\mathrm{p}}$ and $R_{\mathrm{p}}$ were determined from $Z_{1}, Z_{2}$ and $R_{\mathrm{s}}$ for each $f$ by use of (4) and (5).

\subsection{Variation of the Capacitance with Frequency and Concentration}

Two platinum wires with common length were used for obtaining dependence of $C_{\mathrm{p}}$ and $R_{\mathrm{p}}$ on kinds of halides and their concentrations without a reference electrode. Reasons for using the two-electrode system are (i) to keep ionic concentrations in the cell against leakage of ions from the reference electrode, and (ii) to retain the solution resistance in a given arrangement of electrodes geometrically constant in order to discern it from $R_{\mathrm{p}}$. Then the equivalent circuit is given by Fig. 3C. Figures 5A-5Dshow the frequency dependence of $C_{\mathrm{p}}$ at several concentrations of $\mathrm{KF}, \mathrm{KCl}, \mathrm{KBr}$ and $\mathrm{KI}$, respectively. All the values of $C_{\mathrm{p}}$ were linear to $\log (f)$, i.e. $C_{\mathrm{p}}=\left(C_{\mathrm{p}}\right)_{f=1}-k_{1} \log (f)$, regardless of kinds of halides and their concentrations. The ratio, $C_{\mathrm{d}} / C_{\mathrm{p}}$, ranged from 1.01 to 1.03 in the present frequency domain. Since $C_{\mathrm{d}}$ is numerically similar to $C_{\mathrm{p}}$, it has frequency dependence similar to in Fig. 5. The frequency dispersion is thought to be relevant to reformation of double-layer by the solvent dipoles at electrodes[43, 44], movements of ions along both lateral and vertical directions and surface roughness[26, 45, 46]. We do not discuss here a reason for the frequency dispersion.

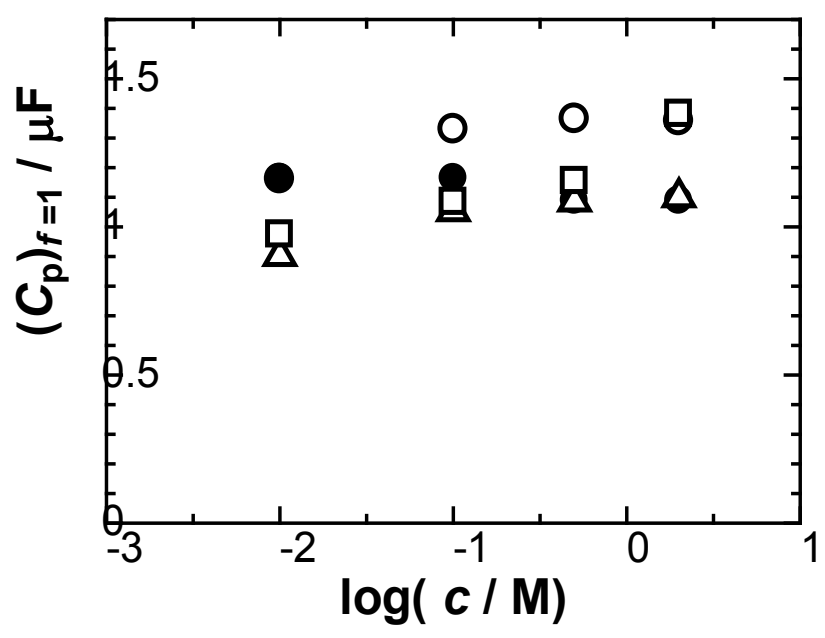

Figure 6. Dependence of $C_{\mathrm{p}}$ at $f=1 \mathrm{~Hz}$ on concentrations of (open circles) $\mathrm{KF}$, (triangles) $\mathrm{KCl}$, (full circles) $\mathrm{KBr}$ and (squares) $\mathrm{KI}$

Values of the slope in Fig. 5 were almost common, $-0.99 \pm$ $0.04 \mu \mathrm{F}$, to four kinds halides in the domain of the concentration. The intercepts of the linear variations in Fig. 5 decreased slightly with a decrease in the concentrations. We choose the parallel capacitance at $f=1 \mathrm{~Hz}$ as a representative of the capacitance for the discussion of dependence on concentrations and kinds of ions. Values of $\left(C_{\mathrm{p}}\right)_{f=1}$ are plotted against concentrations in Fig. 6. Use of low concentrations increases both $Z_{1}$ and $R_{\mathrm{s}}$ in(4), and hence the difference $Z_{1}-R_{\mathrm{s}}$ includes large errors. Accurate evaluation of $R_{\mathrm{s}}$ at low concentrations requires high frequency measurements, at which $\left|Z_{2}\right|$ was overestimated by a property of the potentiostat to yield underestimation of $R_{\mathrm{s}}$. The average value of $\left(C_{\mathrm{p}}\right)_{f=1}$ in Fig. 6 is $(1.2 \pm 0.1) \mu \mathrm{F}$ or $(38 \pm 3) \mu \mathrm{F} \mathrm{cm} \mathrm{cm}^{-2}$.

Concentration dependence of double layer capacitance has seldom been discussed. The GC theory mentions that the double-layer capacitance has the square-root dependence of ionic concentration $[3,4]$. The capacitance at the nitrobenzene|water interface by Wandlowski et al. increased 
with the concentrations, showing the dependence of the square-root of the concentrations [47], similar to the GC theory. The ion-cell model has suggested the dependence of $1 / 3$ powers of the concentration [35]. The almost constant values of $\left(C_{\mathrm{p}}\right)_{f=1}$ common to $\mathrm{F}^{-}, \mathrm{Cl}^{-}, \mathrm{Br}^{-}$and $\mathrm{I}^{-}$indicate that the value of double-layer capacitance should be controlled by solvent molecules rather than ions. This prediction will be proved in latter discussion. The common values have already been reported [36].

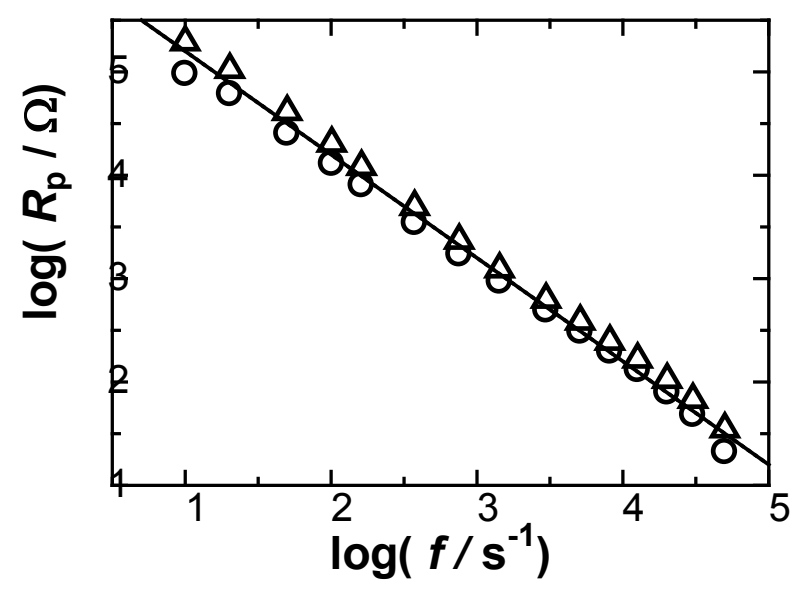

Figure 7. Variations of the parallel resistance with frequency on the logarithmic scale for (circles) $0.5 \mathrm{M} \mathrm{KF}$ and (triangles) $0.5 \mathrm{M} \mathrm{KCl}$

Figure 7 shows the variation of the parallel resistance with frequency for $\mathrm{KF}$ and $\mathrm{KCl}$. The plots for $\mathrm{KBr}$ and $\mathrm{KI}$ overlapped with those for $\mathrm{KF}$ and $\mathrm{KCl}$. The plots were independent of the concentration range of 0.01 to $2 \mathrm{M}$ for the four halides. Since the slope of the lines is -1 , the resistance should be inversely proportional to the frequency. The frequency dependence is caused by $\partial C_{\mathrm{p}} / \partial \omega$ in (1) through the linear variation of $C_{\mathrm{p}}$ with $\log f$. Slopes of the linearity were common to four halides. Therefore, the frequency dependence of $R_{\mathrm{p}}$ should be common to the halides.

\subsection{Potential Dependence of Capacitance and Resistance}

We used the three-electrode system at the Pt wire working electrode in order to obtain variations of the capacitance with dc-potential. Since we confirmed that $C_{\mathrm{p}}$ and $R_{\mathrm{p}}$ were independent of ionic concentrations, fluctuation of ionic concentration by the reference electrode has a negligible effect on $C_{\mathrm{p}}$ and $R_{\mathrm{p}}$. The impedance at the Pt wire electrode in $\mathrm{KF}, \mathrm{KCl}, \mathrm{KBr}$ and $\mathrm{KI}$ solutions at concentrations from 1 $\mathrm{mM}$ to $1 \mathrm{M}$ were obtained at ac voltage superimposed on 0.2 $\mathrm{V}$ vs. $\mathrm{Ag} \mid \mathrm{AgCl}$. The impedance analysis was made by use of the model (A) in Fig. 3. We confirmed that all the values of $R_{\mathrm{p}}$ and $C_{\mathrm{p}}$ were very close to the data obtained at the two electrode system (model (C)). In order to vary the electrode area, we changed the immersed length of the Pt wire from 1 to $11 \mathrm{~mm}$ by $1 \mathrm{~mm}$ per-step. Values of $C_{\mathrm{p}}$ of $\mathrm{KCl}$ were proportional to the area of the electrode, as predicted[40]. In contrast, those of $R_{\mathrm{p}}$ were inversely proportional the area, as shown in Fig. 8.

The inverse proportionality can be explained by inserting $C_{\mathrm{p}}=K A$ into $R_{\mathrm{p}}=(\mathrm{d} t / \mathrm{d} \omega) /\left(\partial C_{\mathrm{p}} / \partial \omega\right), \quad \mathrm{i}, \mathrm{e}, \quad R_{\mathrm{p}}=$ $(\mathrm{d} t / \mathrm{d} \omega) /(A \partial K / \partial \omega)$, where $K$ is a function of $\omega$. This expression is composed of variables of interface, $A$ and $K$, rather than those of bulk solution. Therefore $R_{\mathrm{p}}$ has the property of the interface.

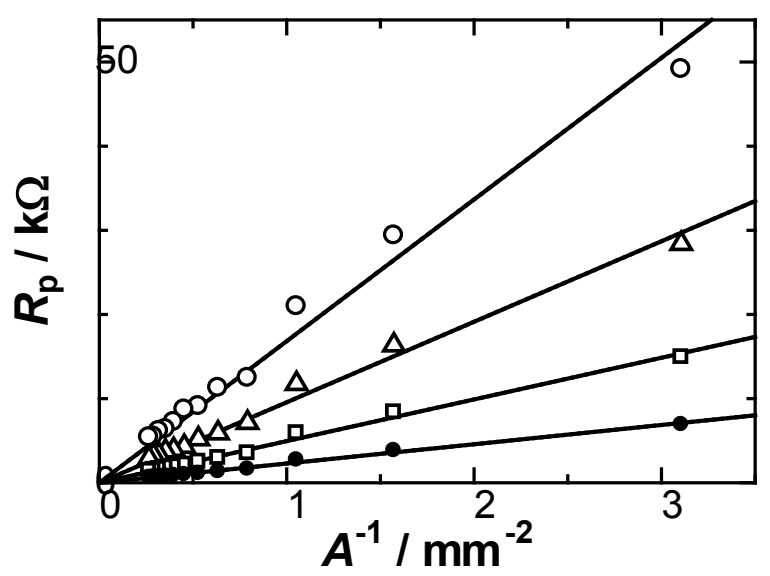

Figure 8. Dependence of $R_{\mathrm{p}}$ of $1.0 \mathrm{M} \mathrm{KCl}$ on the area of the electrode at $f$ $=$ (open circles) 320, (triangles) 541, (squares) 1082 and (full circles) 2475 $\mathrm{Hz}$.

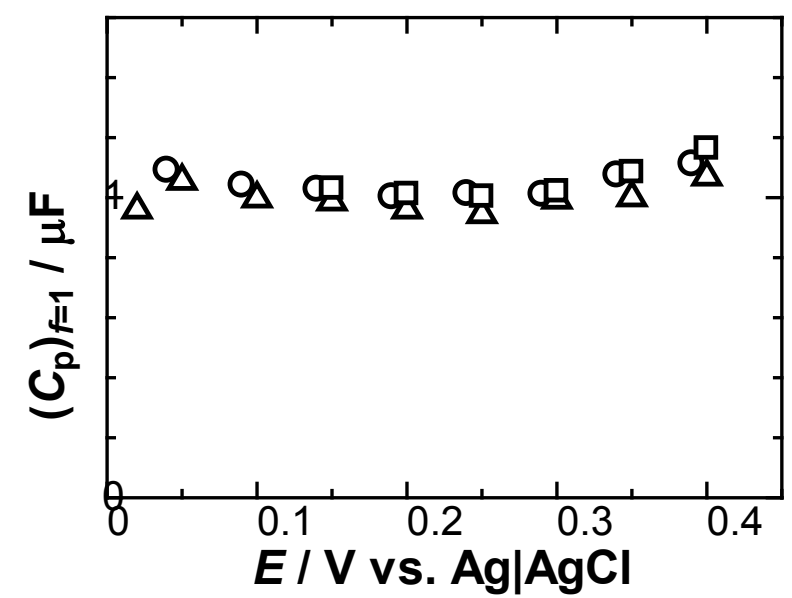

Figure 9. Dependence of the double layer capacitance on dc-potential in $0.1 \mathrm{M}$ solutions of (squares) $\mathrm{KF}$, (circles) $\mathrm{KCl}$ and (triangles) $\mathrm{KBr}$, where the capacitance values are extrapolated to $1 \mathrm{~Hz}$.

Figure 9 shows the plots of $\left(C_{\mathrm{p}}\right)_{f=1}$ in $0.1 \mathrm{M} \mathrm{KF}, \mathrm{KCl}$ and $\mathrm{KBr}$ solutions against the $\mathrm{dc}$ potential, $E$, exhibiting independence of the potential. The negligible variance of $C_{\mathrm{d}}$ vs. $E$ curve was also found in halide ionic solutions[15].

The plots belong actually to the planar shape with $\Delta C_{\mathrm{p}} / C_{\mathrm{p}, \mathrm{av}} \approx 0.1$. The planar shape implies negligible contribution of the electrostatic interaction between ions and the dc-electric field to the capacitance[9, 36], being not satisfied with the GC theory. Consequently, the capacitance is caused mainly by solvent molecules rather than ions. This inference agrees with the invariance of the capacitance to the ionic concentrations (in Fig. 6). The plots in Fig. 9 demonstrate no difference in the capacitance among $\mathrm{KF}, \mathrm{KCl}$ 
and $\mathrm{KBr}$. It has been widely believed that fluoride is a non-specific adsorbed species whereas chloride and bromide are adsorbed specifically on electrodes. This statement may be valid for mercury electrodes $[17,18,41]$, whereas it is invalid for platinum ones. Since iodide solution showed a narrow polarized domain $(0.15 \mathrm{~V})$, it is insignificant to discuss the shape of $C_{\mathrm{p}}$ vs. $E$ curves.

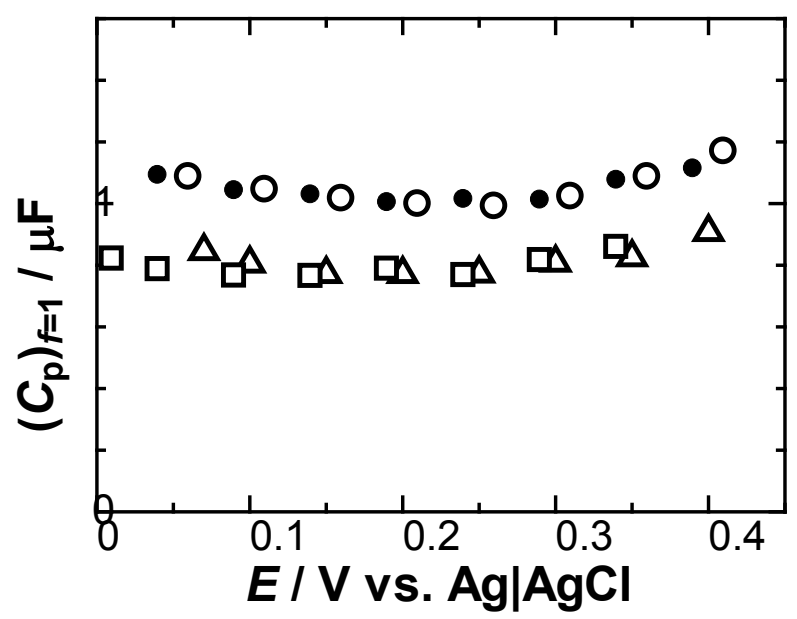

Figure 10. Variations of the double layer capacitance in $\mathrm{KCl}$ solution at (open circles) $1 \mathrm{M}$, (filled circles) $0.1 \mathrm{M}$, (triangles) $0.01 \mathrm{M}$ and (squares) $0.001 \mathrm{M}$ with the dc-potential, where the capacitance values are extrapolated to $1 \mathrm{~Hz}$.

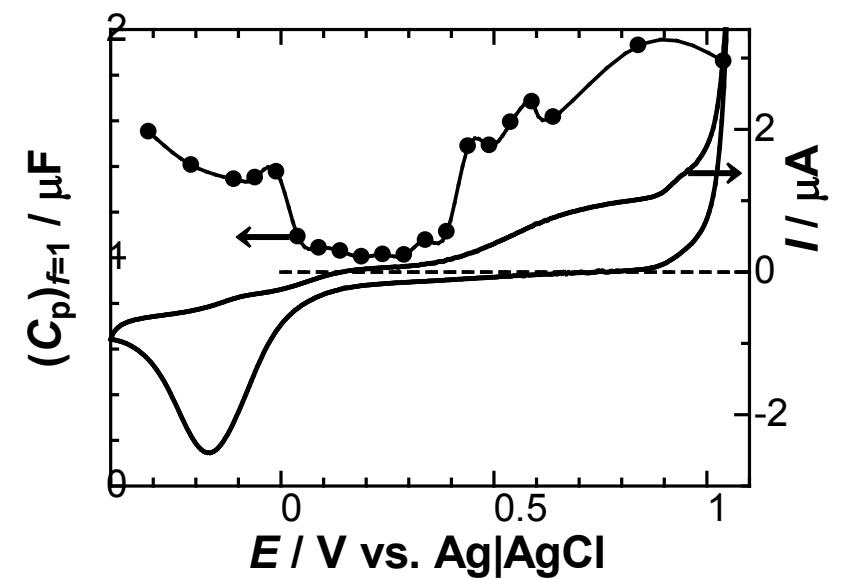

Figure 11. Comparison of the potential-dependence of $\left(C_{\mathrm{p}}\right)_{f=1}$ and cyclic voltammetry in $0.1 \mathrm{M} \mathrm{KCl}$ solutionon.

Figure 10 shows dependence of $\left(C_{\mathrm{p}}\right)_{f=1}$ for $\mathrm{KCl}$ on the dc-potential for several concentrations. No dependence was found even at the lowest concentration $(1 \mathrm{mM})$. Therefore, the electrostatic interaction of ions with the electric field plays a minor role in forming the double layer capacitor. The independence was also observed for $\mathrm{KF}$ and $\mathrm{KBr}$ at the concentrations of the above domain.

Dependence of $C_{\mathrm{p}}$ on concentrations is barely noticeable in Fig. 10 as well as Fig. 5 and 6. We evaluated the solution resistance by means of extrapolating $Z_{1}$ to infinite frequency conveniently in order to avoid deterioration of electrode surfaces by a long term measurements. Values of $R_{\mathrm{s}}$ by this technique were unfortunately smaller than those evaluated from [40] variations of $Z_{1}$ with the distance between the two wire electrodes by $30-50 \%$ when halide concentrations were less than $0.1 \mathrm{M}$. The underestimation of $R_{\mathrm{s}}$ provides smaller values of $C_{\mathrm{p}}$ through (4) than those determined by the latter method. Consequently the values of $C_{\mathrm{p}}$ in Fig. 5, 6, and 10 at low concentrations are smaller than those at high concentrations. The underestimation of $R_{\mathrm{s}}$ by the extrapolation may be due to delay of the potentiostat. Accurate determination of the concentration dependence would require meticulous calibration of a potentiostat, especially at low concentration and high frequency.

Figure 11 shows the variation of double layer capacitance in thewide potential domain, showing a valley shape. The cliff-like variation occurred at the potential which gives rise to faradic reactions, as is compared with the cyclic voltammogram. The increase in the capacitance by faradic currents has been found at $\operatorname{Ir}(100)$ in $0.1 \mathrm{M} \mathrm{HCl}$ [15], and at $\mathrm{Pt}(111)$ electrode in $0.1 \mathrm{M} \mathrm{HClO}_{4}$ [23]. Capacitances with a valley shape reported so far may include faradaic impedance. Participation in the faradaic currents has been applied to electroactive film-coated electrodes in order to enhance capacitance largely [48, 49].

\section{Conclusion}

The double layer impedance is expressed by a parallel combination of the capacitance and the resistance. The latter is not a real resistance, but appears noticeably at low frequency. It is necessarily associated with the measurements of ac impedance through (1). Since it results from the frequency-dependence of the capacitance, it is a property of the double layer. Values of $R_{\mathrm{p}}$ are common to four halides and concentrations, and are independent of dc-potential in the polarized domain.

$C_{\mathrm{p}}$ varies linearly with $\log (f)$ in solutions of four halides at concentrations more than $1 \mathrm{mM}$. This linear variation causes $R_{\mathrm{p}}$ through $1 /\left(\partial C_{\mathrm{p}} / \partial \omega\right) . \quad C_{\mathrm{p}}$ is independent both of dc-potential in the polarized domain and ionic concentration of halides so that the shape of capacitance vs. potential curves is a plane. The capacitance is caused by water molecules rather than ions. A valley shape is possibly ascribed to participation in faradaic currents, i.e., a decrease in the component of the out of phase of faradaic impedance.

\section{Acknowledgements}

This work was financially supported by Grants-in-Aid for Scientific Research (Grant 22550072) from the Ministry of Education in Japan.

\section{REFERENCES}


[1] D. Jiang, D. Meng, J. Wu. Density functional theory for differential capacitance of planar electric double layers in ionic liquids, Chemical Physics Letters, Vol.504, No.4-6, 153-158, 2011.

[2] M.V. Fedorov, N. Georgi, A.A. Kornyshev. Double layer in ionic liquids: The nature of the camel shape of capacitance, Electrochemistry Communications, Vol.12, No.2, 296-299, 2010.

[3] G. Gouy. Constitution of the electric charge at the surface of an electrolyte, J. Phys., Vol.9, No.4, 457-467, 1910.

[4] D.L. Chapman. A contribution to the theory of electrocapillarity, The London, Edinburgh, and Dublin Philosophical Magazine and Journal of Science, Vol.25, No.148, 475-481, 1913.

[5] G. Bell, S. Levine, B. Conway, R. Barradas. Chemical Physics of Ionic Solutions, Wiley, New York, Vol.122, 1966.

[6] S. Levine, G. Bell. Modified Poisson-Boltzmann equation and free energy of electrical double layers in hydrophobic colloids, Discuss. Faraday Society, Vol.42, 69-80, 1966.

[7] S. Levine, G. Bell. Theory of a modified Poisson-Boltzmann equation. I. The volume effect of hydrated ions, The Journal of Physical Chemistry, Vol.64, No.9, 1188-1195, 1960.

[8] F. Silva, C. Gomes, M. Figueiredo, R. Costa, A. Martins, C.M. Pereira. The electrical double layer at the $[\mathrm{BMIM}]\left[\mathrm{PF}_{6}\right]$ ionic liquid/electrode interface - Effect of temperature on the differential capacitance, Journal of Electroanalytical Chemistry, Vol.622, No.2, 153-160, 2008.

[9] I.-T. Kim, M. Egashira, N. Yoshimoto, M. Morita. Effects of electrolytic composition on the electric double-layer capacitance at smooth-surface carbon electrodes in organic media, Electrochimica Acta, Vol.55, No.22, 6632-6638, 2010.

[10] C.H. Kim, S.I. Pyun, J.H. Kim. An investigation of the capacitance dispersion on the fractal carbon electrode with edge and basal orientations, Electrochimica Acta, Vol.48, No.23, 3455-3463, 2003.

[11] L. Siinor, K. Lust, E. Lust. Influence of anion composition and size on the double layer capacitance for $\mathrm{Bi}(111)$ |room temperature ionic liquid interface, Electrochemistry Communications, Vol.12, No.8, 1058-1061, 2010.

[12] V. Lockett, R. Sedev, J. Ralston, M. Horne, T. Rodopoulos. Differential capacitance of the electrical double layer in imidazolium-based ionic liquids: Influence of potential, cation size, and temperature, The Journal of Physical Chemistry C, Vol.112, No.19, 7486-7495, 2008.

[13] G. Láng, K.E. Heusler. Changes of the specific surface energy of gold due to the chemisorption of sulphate, Journal of Electroanalytical Chemistry, Vol.391, No.1-2, 169-179, 1995.

[14] M. Fujihira, A. Tamura, T. Osa. Organo-modified carbon electrodes. I. studies of modified layer via amide bonds by capacitance measurements and ESCA, Chemistry Letters, Vol.6, No.4, 361-366, 1977.

[15] T. Pajkossy, D. Kolb. Double layer capacitance of the platinum group metals in the double layer region, Electrochemistry Communications, Vol.9, No.5, 1171-1174,
2007.

[16] D.C. Grahame. Properties of the Electrical Double Layer at a Mercury Surface. II. The Effect of Frequency on the Capacity and Resistance of Ideal Polarized Electrodes1, Journal of the American Chemical Society, Vol.68, No.2, 301-310, 1946 .

[17] D.C. Grahame. The electrical double layer and the theory of electrocapilarity, Chemical Reviews, Vol.41, 441-501, 1947.

[18] D.C. Grahame. Differential capacity of mercury in aqueous sodium fluoride solutions. I. Effect of concentration at $25^{\circ}$, Journal of the American Chemical Society, Vol.76, No.19, 4819-4823, 1954.

[19] M. Karolczak. Preliminary studies on fitting experimental differential capacitance to theoretical curves, Journal of Electroanalytical Chemistry, Vol.402, No.1-2, 37-46, 1996.

[20] S.E. Moulton, J.N. Barisci, A. Bath, R. Stella, G.G. Wallace. Studies of double layer capacitance and electron transfer at a gold electrode exposed to protein solutions, Electrochimica Acta, Vol.49, No.24, 4223-4230, 2004.

[21] M.T. Alam, M.M. Islam, T. Okajima, T. Ohsaka. Measurements of differential capacitance at mercury/room-temperature ionic liquids interfaces, The Journal of Physical Chemistry C, Vol.111, No.49, 18326-18333, 2007.

[22] T. Wandlowski, J. Wang, B. Ocko. Adsorption of bromide at the Ag (100) electrode surface, Journal of Electroanalytical Chemistry, Vol.500, No.1, 418-434, 2001.

[23] T. Pajkossy, D. Kolb. Double layer capacitance of Pt (111) single crystal electrodes, Electrochimica Acta, Vol.46, No.20, 3063-3071, 2001.

[24] M.G.H.M. Hendriks, J.E. ten Elshof, H.J.M. Bouwmeester, H. Verweij. The electrochemical double-layer capacitance of yttria-stabilised zirconia, Solid State Ionics, Vol.146, No.3-4, 211-217, 2002.

[25] B. Conway, A. Zolfaghari, W. Pell, G. Jerkiewicz. Voltammetry, nanogravimetry and double-layer capacitance studies on chemisorption of $\mathrm{Cl}$-and $\mathrm{Br}$-, competitive with potential-dependent electrosorption of $\mathrm{O}$ species at $\mathrm{Pt}$ electrodes, Electrochimica Acta, Vol.48, No.25-26, 3775-3778, 2003.

[26] R.S. Neves, E.D. Robertis, A.J. Motheo. Capacitance dispersion in EIS measurements of halides adsorption on $\mathrm{Au}$ (2 1 0), Electrochimica Acta, Vol.51, No.7, 1215-1224, 2006.

[27] K.B. Oldham. A Gouy-Chapman-Stern model of the double layer at a (metal)/(ionic liquid) interface, Journal of Electroanalytical Chemistry, Vol.613, No.2, 131-138, 2008.

[28] G. Valette. Double layer on silver single crystal electrodes in contact with electrolytes having anions which are slightly specifically adsorbed: Part II. The (100) face, Journal of Electroanalytical Chemistry and Interfacial Electrochemistry, Vol.138, No.1, 37-54, 1982.

[29] B. Piela, P.K. Wrona. Capacitance of the gold electrode in $0.5 \mathrm{MH}_{2} \mathrm{SO}_{4}$ solution: ac impedance studies, Journal of Electroanalytical Chemistry, Vol.388, No.1, 69-79, 1995.

[30] V.D. Jović, B.M. Jović. EIS and differential capacitance 
measurements onto single crystal faces in different solutions: Part I: $\mathrm{Ag}(111)$ in $0.01 \mathrm{M} \mathrm{NaCl}$, Journal of Electroanalytical Chemistry, Vol.541, No.0, 1-11, 2003.

[31] P.S. Germain, W.G. Pell, B.E. Conway. Evaluation and origins of the difference between double-layer capacitance behaviour at Au-metal and oxidized $\mathrm{Au}$ surfaces, Electrochimica Acta, Vol.49, No.11, 1775-1788, 2004.

[32] B. Łosiewicz, R. Jurczakowski, A. Lasia. Kinetics of hydrogen underpotential deposition at polycrystalline rhodium in acidic solutions, Electrochimica Acta, Vol.56, No.16, 5746-5753, 2011.

[33] S. Aberg. Measurement of uncompensated resistance and double layer capacitance during the course of a dynamic measurement: correction forIRdrop and charging currents in arbitrary voltammetric techniques, Journal of Electroanalytical Chemistry, Vol.419, No.1, 99-103, 1996.

[34] K.L. Yang, S. Yiacoumi, C. Tsouris. Electrosorption capacitance of nanostructured carbon aerogel obtained by cyclic voltammetry, Journal of Electroanalytical Chemistry, Vol.540, 159-167, 2003.

[35] K. Aoki. Ion-cell model for electric double layers composed of rigid ions, Electrochimica Acta, Vol.67, No.0, 216-223, 2012.

[36] M.A.V. Devanathan, K. Ramakrishnaiah. Differential capacitance of some solid metal/aqueous-electrolyte interfaces, Electrochimica Acta, Vol.18, No.3, 259-264, 1973.

[37] I. Paseka. Influence of hydrogen absorption in amorphous $\mathrm{Ni}-\mathrm{P}$ electrodes on double layer capacitance and charge transfer coefficient of hydrogen evolution reaction, Electrochimica Acta, Vol.44, No.25, 4551-4558, 1999.

[38] W.G. Pell, A. Zolfaghari, B.E. Conway. Capacitance of the double-layer at polycrystalline $\mathrm{Pt}$ electrodes bearing a surface-oxide film, Journal of Electroanalytical Chemistry, Vol.532, No.1, 13-23, 2002.

[39] T. Pajkossy, D. Kolb. On the origin of the double layer capacitance maximum of Pt (111) single crystal electrodes, Electrochemistry Communications, Vol.5, No.4, 283-285, 2003.

[40] K. Aoki, Y. Hou, J. Chen, T. Nishiumi. Resistance associated with measurements of capacitance in electric double layers, Journal of Electroanalytical Chemistry, Vol.689, 124-129, 2013.

[41] D.C. Grahame. Electrode processes and the electrical double layer, Annual Review of Physical Chemistry, Vol.6, No.1, 337-358, 1955 .

[42] E.J. Dickinson, R.G. Compton. How well does simple RC circuit analysis describe diffuse double layer capacitance at smooth micro-and nanoelectrodes?, Journal of Electroanalytical Chemistry, Vol.655, No.1, 23-31, 2011.

[43] A.J. Motheo, A. Sadkowski, R.S. Neves. Electrochemical immittance spectroscopy applied to the study of the single crystal gold/aqueous perchloric acid interface, Journal of Electroanalytical Chemistry, Vol.430, No.1-2, 253-262, 1997.

[44] A. Sadkowski, A.J. Motheo, R.S. Neves. Characterisation of $\mathrm{Au}(111)$ and $\mathrm{Au}(210) /$ aqueous solution interfaces by electrochemical immittance spectroscopy, Journal of Electroanalytical Chemistry, Vol.455, No.1-2, 107-119, 1998.

[45] Z. Kerner, T. Pajkossy. On the origin of capacitance dispersion of rough electrodes, Electrochimica Acta, Vol.46, No.2-3, 207-211, 2000.

[46] W. Scheider. Theory of the frequency dispersion of electrode polarization. Topology of networks with fractional power frequency dependence, The Journal of Physical Chemistry, Vol.79, No.2, 127-136, 1975.

[47] T. Wandlowski, K. Holub, V. Mareček, Z. Samec. The double layer at the interface between two immiscible electrolyte solutions-IV. Solvent effect, Electrochimica Acta, Vol.40, No.18, 2887-2895, 1995.

[48] P.J. Kulesza, M. Skunik, B. Baranowska, K. Miecznikowski, M. Chojak, K. Karnicka, E. Frackowiak, F. Béguin, A. Kuhn, M.-H. Delville. Fabrication of network films of conducting polymer-linked polyoxometallate-stabilized carbon nanostructures, Electrochimica Acta, Vol.51, No.11, 2373-2379, 2006.

[49] L. Niu, C. Kvarnström, A. Ivaska. Evaluation of coverage of self-assembled polyaniline-analogue monolayer by capacitance measurements, Journal of Electroanalytical Chemistry, Vol.600, No.1, 95-102, 2007. 